\title{
Diagnosis of aortic coarctation by tardus-parvus renal artery Doppler signal in an infant with multicystic dysplastic kidney: a case report
}

Kate Park • Kieran McHugh • William van't Hoff

Published online: 10 February 2007

(C) Springer-Verlag 2007

Pediatr Radiol DOI 10.1007/s00247-006-0371-3

The name of the third author is William van't Hoff.

The online version of the original article can be found at http://dx.doi. org/10.1007/s00247-006-0371-3.

K. Park $(\bowtie) \cdot$ K. McHugh

Department of Radiology, Great Ormond Street Hospital for Children,

London WC1N 3JH, UK

e-mail: katerissik@hotmail.com

W. van't Hoff

Department of Nephrology, Great Ormond Street Hospital for Children,

London, UK 